\begin{tabular}{ll}
\hline & $\begin{array}{l}\text { Kastamonu Eğitim Dergisi } \\
\text { Kastamonu Education Journal }\end{array}$ \\
$\begin{array}{ll}\text { Mayıs } 2019 \text { Cilt:27 Sayı:3 } \\
\text { kefdergi.kastamonu.edu.tr }\end{array}$ \\
\hline
\end{tabular}

\title{
Üstün Zekâlı ve Yetenekli Çocukların Erken Çocukluk Döneminde Tanılanmasında Öğretmenlerin Düşünceleri
}

\section{Teachers' Opinions on Identifiying Gifted and Talented Children at Early Childhood Period}

\section{Öz}

\author{
Çağlar ÇETINKAYA ${ }^{1}$, Gamze iNCi²
}

Bu çalışmanın amacı, erken dönemde üstün zekâlı ve yetenekli çocukların tanılanmasında BíLSEM öğretmenlerinin düşüncelerini belirlemektir. Çalışmaya, Trabzon Bilim ve Sanat Merkezi (BiLSEM)'de görev yapmakta olan toplam 14 öğretmen katımıştır. Araştırmadan elde edilen veriler araştırmacı tarafindan oluşturulan "Görüşme Formu" ile toplanmış ve nitel araştırma yöntemlerine uygun olarak analiz edilmiştir. Araştırmada, nitel verilerin kullanıldığı durum çalışması deseni kullanılııştr. Çalışmanın bulguları, Trabzon BiLSEM öğretmenlerinin üstün zekâlı ve yetenekli çocuklar hakkında yeterli bilgiye sahibi olduklarını, bu çocukların farklı özelliklerini bildikleri, üstün zekâlı ve yetenekli çocukların erken tanılanmalarına işaret etmektedir.

Anahtar Kelimeler: Erken çocukluk eğitimi, Üstün zekâlı ve yetenekli çocuk, BiLSEM, Tanılama

\section{Abstract}

The purposes of this study, the identification of gifted children in preschool teachers' think to determine the Science Art Center (SAC). The study, which is working in Trabzon SACs total of 14teachers, participated. The data obtained from the study by researcher screated "Interview Form" and collected and analyzed according to qualitative research methods. In this study, case study research design that requires qualitative data was used. The study's findings, Trabzon SAC teachers of gifted children that they have enough information about these children, they are defined in terms of different features, identification of gifted children indicates that they are contributing to the stage.

Keywords: Early childhood education, Gifted and talented children, SAC (Gifted School), Identification

1. Akdeniz Üniversitesi, Eğitim Fakültesi, Antalya, Türkiye; https://orcid.org/0000-0002-1943-7873 


\section{Extended Summary}

Introduction: One of the significant causes for human advancement in science is intelligence. Developed societies have generally made progress by means of products of intelligence and there is no society that has achieved something without an educated intelligence. In this regard, an accurate description of concept of intelligence is necessary as it is a leading criteria for representing gifted and talented individuals. For many years, intelligence could not be clearly defined (Topses, 1992). Although there was no common definition among the researchers, many of them took similar criteria into account while defining intelligence. Having taken such criteria into account, Stenberg (1999) considered intelligence to be components of: perception, noticing similarities and differences, being careful, sensitivity, strong memory, imagination, reasoning skills, abstract thinking and adaptation.

Gifted and talented individuals are important resources for societies. Yet these individuals are rarely encountered in societies. While their percentage is stated to be $2.3 \%$ in Marland Report (1972). The earlier abilities of gifted and talented children are identified, the more success in their education can be achieved (Moore, 1992). Moreover, it is easy to make plans for future of children that are accurately identified at an early period. If gifted and talented children are identified at an early period, their social and emotional development, and particularly their cognitive development will progress better (Schofield and Hotulainen, 2004; Stapf, 2003). Teachers have more information than any other about gifted and talented children. Therefore, during identification, teacher quality affects the efficiency of the process (Şahin and Çetinkaya, 2015).

The aim of this study is to determine opinions of BILSEM teachers on identifying gifted and talented children at preschool period. In line with this aim, answers for the questions were seeked; 1 ) What is giftedness and talent? 2) What characteristics do you think gifted and talented children at preschool possess? 3) When should gifted and talented children be identified? 4) What reasons could there be for identifying gifted and talented children at an early period?

Methods: This is a descriptive study that was carried out with qualitative data. In this study, case study research design that requires qualitative data was used. Case studies are defined as an empirical and qualitative research model that sets forth a descriptive explanation and analysis on one or more cases and that evaluates a current issue within its own course (Johnson and Cristensen, 2014; Merriam, 2009; Patton, 2014; Yıldırım and Şimşek, 2013).

14 Trabzon SAC teachers that were chosen by means of convenience sampling method among other research oriented sampling methods, participated in the study. Because convenience sampling picks close and easily accessible people, it makes the study quicker and more practical (Yıldırım and Şimşek, 2013). Data is collected from interviews made with 14 teachers working in 2013-2014 school year. Participation in this study is on a voluntary basis. 7 of the participants were male and 7 of them were female. Among the participant teachers; overall age range changed between 38 and 57, years of professional experience changed between 12 and 35, and years of experience at SAC changed between 4 and 12. Among the participant teachers; 2 of them were class teachers, 2 of them were guidance and psychological counseling teachers, 2 of them were physics teachers, 2 of them were music teachers, and the rest were literature, geography, science and maths teachers with one of each.

In order to determine demographic characteristics of the teachers, "Personal Information Form" prepared by the researcher was implemented during the study. Furthermore, data obtained during the study was collected by means of "Semi-structured Interview Form". "Semi-structured Interview Form" was composed after relevant literature was reviewed and expert opinions were taken. Interview form consists of 4 questions that are to respond to goal and subgoals. Each interview lasted for about 15-20 minutes and then they were transcribed. Data obtained throughout the study was analyzed by means of descriptive content analysis method which is one of the content analysis methods. In the general sense, content analysis is collection of oral or written documents under specific themes after they are examined in an objective and systematic way (Bogdan and Biklen, 2007).

Finding and Discussion: As a result of this study, it was determined that SAC teachers are adequately informed about gifted and talented children at early childhood; that they know these children in terms of their distinctive characteristics; and that they are well-equipped regarding need for early identification and timely identification of gifted and talented children. According to the results of the study, it is also suggested that early identification of gifted and talented children is very crucial for them to become socially beneficial individuals. Identification of gifted and talented children makes it essential for them to benefit from early education programs. Teachers and families of gifted and talented children should be conscious.

Recommendations concluded according to the results of the study are as follows: There should also be national policies developed in order for these children to be identified and provided with education suitable for their abilities starting from early childhood. Training programs and seminars for families and particularly for teachers should be organized to raise awareness. Even if SAC teachers are not working with preschool children, they should be equipped about working with gifted and talented children at early period that reflect almost same characteristics with the age group they are actually working with. 


\section{Giriş}

Üstün zekâlı ve yetenekli bireyleri ifade etmede önemli kriterlerin başında olan zekâ kavramının doğru şekilde nitelenmesi gelmektedir. Zekânın uzun yıllar boyunca net bir tanımı yapılamamıştır (Topses,1992). Her ne kadar ortak tanım yapılmasa da birçok araştırmacı benzer kriterleri dikkate alan tanımlarda bulunmuşlardır. Bu kriterleri dikkate alan Stenberg (1999) zekâyı; algılama, benzerlik ve farklıııları yakalayabilme, dikkatli olma, duyarlılık, güçlü hafiza, hayal gücü, muhakeme becerileri, soyut düşünebilme be uyum bileşenleri olarak ele almıştır. Yine Sternberg, Jarvin ve Grigorenko'ya göre (2010) zekâ öğrenmede üst bilişsel kullanarak çevreye uyum sağlama deneyimidir.

\section{Üstün Zekâlı ve Yetenekliler}

Üstün zekâlı ve yetenekli bireyler toplum için önemli bir kaynaktıllar. Bu bireylere her toplumda düşük oranda rastlanmaktadırlar. Marland Raporunda (1972) bu oran \%2,3 olarak belirtilirken farklı araştırmalarda değişmektedir. Webb, Meckstroth ve Tolan (2003), üstün zekâlı ve yetenekli bireyleri toplumlarının genelinin üst \%1,5 ile \%3 dilimi arasında nitelemektedir.

Zekâda olduğu gibi üstün zekâlı ve yetenekli bireyleri de tanımlamakta da zorluk çekilmiştir. İlk tanımlar kalıtımı gerekçe gösteren kısa açıklamalarken sonraki tanımlar çok boyutlu yapıdadır. Uzun (2004), üstün zekâlı ve yetenekli bireyi 130 ZB ve üstü skora sahip bireylerdir şeklinde ifade etmektedir. Özbay’a göre (2013), üstün zekâ, genel zihinsel potansiyeldir. Sousa'ya göre (2003), yüksek zekâ bölümü (ZB), üstün zekâ ve yeteneği tanımlamaktadır. Harrison'a göre (2004), üstün zekâlı ve yetenekli çocuklar akranlarından en az bir alanda ileri performans gösteren çocuklardır. Gagné (2003) üstün zekâlı ve yetenekli bireyi akranlarına göre en az \%10 üst bilgi ve donanıma sahip olanlar şeklinde tanımlamaktadır. Sisk'e göre (1987) üstün zekâlı ve yetenekli birey, yüksek kapasiteli iş yapabilme becerisi uzmanlarca kanıtlanmış bireydir. Freeman (1985), üstün zekâ ve yeteneği; bir alanda güçlerini en üst düzeyde ortaya koyan kişiler şeklinde ifade etmektedir.

Bu tanımlara ek olarak zekâyı çok boyutlu bütün olarak gören tanımlarda vardır. Bu tanımlar özellikle çevresel faktörleri dikkate almaktadır (Damasio, 1999; Davaslıgil, 2004; Sternberg, 2003). Miklewska, Kaczmarek ve Straleu (2006), zekâ gelişiminin çevreden etkilendiğini belirtmektedir. Weiten (1995), zekâda çevrenin etkisinin varlığından söz etmektedir. Üstün zekâlı ve yetenekli çocuk; zekâ, yaratıcılık, akademik başarı, sanat ve liderlik alanlarından akranlarından ileri olan bireyler olarak tanımlanmıştır (Bilim ve Sanat Merkezi Yönergesi, 2016). Maker (2003), üstün yeteneği; ilgiler, istekler ve problem çözme yeteneklerinin birleşimi olarak ifade etmektedir. Baykoç’a göre (2011) üstün zekâ ve yetenek, kalıtımla bahşedilen ve çevre etkisi ile bir ya da fazla alanda ortaya çıkmış özelliklerdir. Bu özellikler kendi akran gurubundan ileridir ve psikometrik araçlar ile ölçülebilir. Koshy (2001), üstün yetenekli bireyler için zekâ, yaratıcılık, liderlik, sanat, fiziki yeteneklere sahiplerdir diye belirtmektedir. Winner (1996) üstün zekâlı ve yetenekli bireyleri zihinsel gücü yüksek, yaratıcı ve görev sorumluluğu olan bireyler olarak ifade etmektedir. Feldhusen ve Kollof'a göre (1986) üstün zekâ ve yetenek; genel ve özel yetenek alanı, kendilik ve motivasyonun bileşkesidir. Bu bireylerin genel özellikleri yüksek zihinsel kapasitelerinin gelişmesine bağlı olan üst bilişsel,sosyal ve duygusal özelliklerdir (Cutts ve Mooseley, 2001; Heller ve Schofield, 2008;Passow, 2004; Renzulli, 1978; Sak, 2010; Tuttle ve Becker, 1980).

\section{Erken Dönemde Üstün Zekâ ve Yeteneklilerin Tanılanması}

Üstün zekâlı ve yetenekli çocukların yeteneklileri ne kadar erken tespit edilirse eğitimlerinde de o kadar başarı sağlanmaktadır (Moore, 1992). Erken dönemde doğru tanılanan çocuklar için geleceğe yönelik plan oluşturmak kolaydır (Schofield ve Hotulainen, 2004; Stapf, 2003). Erken dönemde üstün zekâlı ve yetenekli bir çocuğu tespit edebilmek için birçok farklı veriye intiyaç vardır. Erken dönemde üstün zekâlı ve yetenekli çocukları tespit etmek oldukça zordur. Çocukların gelişimi en hızlı alt yaşına kadardır. Tanılamanın nasıl ve hangi araçlarla yapılacağı tartı̧malara neden olmaktadır (Cutts ve Moseley, 2004; Pfeiffer, 2008). Zekânın (IQ) tespitinde genel olarak zekâ testleri kullanılmaktadır. Zekâ testleri genellikle altı ve üzeri yaştaki çocukların tanılanmasında geçerli ve güvenilir sonuçlar vermektedir (Hodge ve Kemp, 2002). Zekâ testlerinde sınırlıı̆ı̆ ortadan kaldırmak için gelişim testlerinden yararlanılmaktadır. Bu da güvenilirliğe ilişkin soru işaretleri oluşturmaktadır (Alma, 2015). Bu dönemde standart test mi yoksa aile ve öğretmen gözlemine dayalı veriler mi kullanılacağı net değildir. Yaygın olarak kullanılan iki farkı tür; yeteneğe dayalı ve psikometrik ölçeklerdir. Güncel çalışmalar bu iki türü birlikte kullanarak bütüncül sonuçlar elde etmektedir (Heller, 2001; Heller, Perleth ve Lim, 2005).

Üstün zekâlı ve yetenekli öğrencilerin tanılanması onların başta bilişsel becerileri olmak üzere diğer becerilerinin formal ve informal araçlarla değerlendirilme sürecidir (Ercan, 2013; Karadağ, 2015).Türkiye'de erken çocukluk döneminde üstün zekâlı ve yetenekli çocukların tanılanmasına yönelik süreç/basamaklar aday gösterme, ön değerlendirme, 
grup tarama, bireysel inceleme, kayıt ve yerleştirme şeklinde gerçekleşmektedir (MEB, 2009; MEB, 2016). Üstün zekâlı ve yetenekli çocukların kendilerine özgü bilişsel, duyusal, sosyal, ahlaki birçok özelliği vardır (Alma, 2015; Çetinkaya, 2013b). Bu özellikleri ölçmek için kullanılan formal verilerin sınırlılıkları öğretmen görüşleri ile desteklenmektedir. Çocukların yeteneklerinin erken dönemde fark edilebilmesi için aile ve öğretmen önemli iki faktördür. Çünkü erken çocukluk döneminde çocuğu gözlemleme gücü en yüksek olan kişiler bunlardır. Erken dönemde üstün zekâlı ve yeteneklilere yönelik olarak çalışmalarının en önemli bölümünü tanılanmaları ve öğretmen farkındalığııın artırılması şeklinde ifade etmek mümkündür (Akar, 2012; Porter,1999).

\section{Erken Dönem Tanılamada Öğretmen;}

Üstün zekâ ve yeteneğin net şekilde ortaya koyulabilmesi için onu niteleyecek özellikler iyi bilinmelidir. Üstün zekâ ve yeteneğin tanı kriterleri bu çocukların akranlarından farklılaşan özellikleri ile benzerlik göstermektedir. Bu anlamda öğretmenlerin tanı kriterleri konusunda yeterli bilgi sahibi olması gerekmektedir. Öğretmenlerin bu hazır bulunuşluğu tanılamayı yapacak olan uzmana büyük katkılar sağlayacaktır (Heller ve Schofield, 2008). Kelemen'e göre (2012), tanılamada kullanılacak en önemli veriler gözlem ve kontrol listeleri ile elde edilir. Üstün zekalı ve yeteneklilerin genel özelliklerinden ileri öğrenme kapasitesi, yaratıcılık ve motivasyon gibi veriler toplanmaya çalışılır.

Öğretmenler üstün zekâlı ve yetenekli çocuklar hakkında en fazla bilgiye sahiptirler. Tanılama süresince öğretmen niteliği verimi etkilemektedir (Şahin ve Çetinkaya, 2015) Formasyon becerileri, aldığı eğitim ve çocukla geçirdikleri zaman dikkate alındığında çocuklar hakkında en fazla bilgiye sahip kişinin öğretmen olması beklenmektedir. Öğretmen çocukları sürekli gözleme ve yeteneklerini deneyimle firsatına sahiptirler. Türkiye'de üstün zekâlı ve yetenekli bireylere eğitim yaygın olarak Bilim ve Sanat Merkezlerinde (BILSEM) verilmektedir (Çetinkaya, 2013a). BíLSEM'lerde okul öncesi dönemde eğitim verilmemektedir. Üstün zekâlı ve yetenekli çocukların erken dönemde tanılanmalarında öğretmen nitelikleri konusunda zorluklar yaşanmaktadır. BiLSEM'de okul öncesi dönem programı olmadığı için BíLSEM öğretmenleri de erken çocukluk dönemi üstün zekâlı çocukları hakkında bilgi sahibi olamamaktadır. Öğretmenlerin erken dönemde üstün zekâlı çocuklar konusunda eğitim alma firsatlarının olmaması çocukların yeteneklerini fark etmede zorluk yaşatmaktadır (Porter,1999).

\section{Araştırmanın Amacı}

Bu çalışmanın amacı, okul öncesi dönemde üstün yetenekli çocukların tanılanmasında BíLSEM öğretmenlerinin düşüncelerini belirlemektir. Bu amaç doğrultusundan aşağıdaki sorulara yanıt aranmıştr.

1)Üstün zekâ ve yetenek nedir? 2) Okul öncesi dönemdeki üstün zekâlı ve yetenekli çocukların hangi özelliklere sahip olduğunu düşünürsünüz? 3) Üstün zekâlı ve yetenekli çocukların ne zaman tanılanmalıdır? 4) Üstün zekâlı ve yetenekli çocukların erken dönemde tanılanması için gerekçeler ne olabilir?

\section{Yöntem}

Bu araştırma, nitel veriler kullanılarak yapılmış olan betimsel bir çalışmadır. Araştırmada, nitel verilerin kullanıldığı durum çalışması deseni kullanılmıştı. Durum çalışmaları bir ve ya birden fazla durum ile alakalı betimsel bir açıklama ve analiz ortaya çıkaran, güncel bir konuyu kendi yaşam olgu içinde değerlendiren görgül ve nitel bir araştirma deseni olarak tanımlanmaktadır (Johnson ve Cristensen, 2014; Merriam, 2009; Yıldırm ve Şimşek, 2013). Durum çalışmalarında genel amaç ise, ele alına bir durum ve ya birden fazla durum hakkında kapsamlı ve detaylı toplanan bilgileri bütüncül bir şekilde analiz etmektir (Yıldırım ve Şimşek, 2013; Patton, 2014).

\section{Araştirma Grubu}

Araştırmaya amaçlı örnekleme yöntemlerinden kolay ulaşılabilir durum örneklemesi yoluyla seçilen 14 Trabzon Bilim Sanat Merkezi öğretmeni katılmıştır. Kolay ulaşılabilir durum örneklemesi yakın ve kolay erişimli kişileri seçtiğinden araştırmaya hız ve pratiklik kazandırır (Yıldırım ve Şimşek, 2013). Veriler 2013-2014 öğretim yılında görev yapan 14 öğretmenle yapılan görüşmeler sonucunda elde edilmiştir. Çalışma grubunda katılım gönüllülük esasına dayanmaktadır. Katılımcıların 7'si erkek, 7'si bayandır. Katılımcı öğretmenlerin genel yaş Aralıkları 38 ile 57 arasında, mesleki deneyim yılları 12 ile 35 arasında, BíLSEM 'deki deneyim yılları 4 ile 12 arasında değişmektedir. Katlımcı öğretmenlerin 2'si sınıf öğretmeni, 2'si rehberlik psikolojik danışman, 2'si fizik, 2'si resim, 2'si müzik, 1'i edebiyat, 1'i coğrafya, 1'i fen bilgisi, 1'i matematik öğretmenidir. Araştırmada her bir katılımcıya K1,K2, şeklinde kodlar verilmiştir.

\section{Veri Toplama Araçları}

Araştırmada, öğretmenlere yönelik demografik özelliklerin belirlenmesi amacıyla araştırmacı tarafindan hazırlanan 
"Kişisel Bilgi Formu" uygulanmıştr. Ayrıca araştırmada elde edilen veriler araştırmacı tarafindan oluşturulan "Yarı-yapılandııımış Görüşme Formu" ile toplanmıştır. Yarı-yapılandırılmış görüşmelerde katılımcılara önceden sorulması planlanan sorular yöneltilir ve gerekli görülen yerlerde yeni sorular eklenebilir veya bazı soruların sorulmasından vazgeçilebilir (Karasar, 2011). Görüşmelerin her biri yaklaşık 15 - 20 dakika sürmüştür. Ardından görüşmeler sırasıyla yazılı metinlere dönüştürülmüştür.

\section{Verilerin Analizi}

Araştırmadan elde edilen veriler içerik analizi türlerinden biri olan betimsel içerik analizi yöntemi kullanılarak analiz edilmiştir. Genel anlamda içerik analizi, sözel veya yazılı belgelerin nesnel ve sistematik bir şekilde incelenerek belirli temalar altında toplanmasıdır (Bogdan ve Biklen, 2007). Betimsel analiz çeşitli veri toplama teknikleri ile toplanmış verilerin önden belirlenmiş temalara göre özetlenip yorumlanması olarak tanımlanan bir nitel analiz türüdür (Yıldırım ve Şimşek, 2013).

\section{Bulgular ve Yorumlar}

Öğretmenlere yöneltilen ilk soru “Üstün zekâ ve yetenek nedir?” olmuştur. Öğretmenlerin soruya vermiş oldukları yanitlar Tablo-1'de verilmiştir.

\section{Tablo 1.Öğretmenlerin Üstün Zekâ ve Yeteneğin Ne Olduğuna illişkin Görüşleri}

\begin{tabular}{ll}
\hline Kod & $f$ \\
\hline Yüksek seviyede zihinsel kapasite $(1,3,4,6,7,8,10,13)$ & 8 \\
Akranlarından her alanda ileri seviye $(1,2,3,6,7,10,11,12)$. & 8 \\
Kolay öğrenebilmek becerisi $(3,4,6,7,8,13)$. & 6 \\
Var olan performansın üst düzey kullanımı $(2,6,8,9,11)$. & 5 \\
Bilişsel becerilerin kullanabilme kabiliyeti $(4,5,6,7,13)$. & 5 \\
Farklı yetenekleri birleştirerek ürün sergilemek $(6,8,9)$. & 3 \\
Yüksek farkındalık düzeyi $(6,7,10)$. & 3 \\
Keşfetme ve buluş yeteneği $(8,11)$ & 2 \\
Farklı kavramlar arasında ilişkiler kurabilme (4) & 1 \\
\hline
\end{tabular}

Tablo-1'de yer aldığı üzere üstün zekâ ve yeteneği ifade eden öğretmenlerin 8'i yüksek seviyede zihinsel kapasite, yine $8^{\prime} i$ akranlarından her alanda ileri seviye, 6'sı kolay öğrenebilme becerisi, 5 'i var olan performansın üst düzey kullanımı, 5'i bilişsel becerileri kullanabilme kabiliyeti, 3'ü farklı yetenekleri birleştirerek ürün sergilemek, 3'ü yüksek farkındalık düzeyi, 2'si keşfetme ve buluş yeteneği, 1'i de farklı kavramlar arasında ilişkiler kurabilme olarak ifade etmişlerdir. Bu düşüncelere ilişkin öğretmenlerin ifadeleri sırası ile aşağıda yer almaktadır.

Ö1: “(...) öğrenci zaten yüksek bir zihinsel kapasiteye sahip olmadan üstün bir zekâ ve üstün bir yetenek olamayacaktır". Ö2: "(...) üstün zekâlı ve yetenekli çocuk kendi akranlarından her bakıma ileridedir. Küçüklükten bellidir." Ö3: "(...) bu çocukların kolay öğrenebildikleri rahat şekilde gözlemlenmektedir". Ö4: "(...) bu çocuklar zekiler ve bu zekâlarını her alanda en üst düzeyde kullanabilmekteler." Ö5: "(...) daha çok zekâya dayalı becerilerini kullanabilen bireyler olduklarını düşünüyorum.". Ö6: "(...)birçok alanda yetenekli oldukları için yaptikları çalışmalarda tek bir yeteneğe değil çoklu yeteneğe dayalı ürünler görmek mümkün". Ö7: "(...)her şeyin farkında olanlardır. Başka şeyle uğraşırken bile sizi eksiksiz dinletip sorulara cevap verebilmek diyebiliriz.". Ö8: "(...)merak ve sorgulayarak bir şeyleri keşfetmek ve buluş yapmaktr"...

Öğretmenlere ikinci soru olarak "Okul öncesi dönemdeki üstün zekâlı ve yetenekli çocukların hangi özelliklere sahip olduğunu düşünürsünüz?" sorulmuştur. Öğretmenlerin soruya verdikleri cevaplar Tablo 2'de verilmiştir.

Tablo 2. Öğretmenlerin Çocukların Hangi Özelliklere Sahip Olduğuna ilişkin Görüşleri

\begin{tabular}{ll}
\hline Kod & $f$ \\
\hline Gelişimin kritik dönemlerini ve zihinsel faaliyetleri erken tamamlama $(2,3,4,5,6,7,8,13)$ & 8 \\
Uyaranlara farklı boyutlarda bakabilme $(3,5,7,10,11,12)$ & 6 \\
Merakıyla çok soru sorma ve ikna olmama $(1,2,3,5,6,11)$ & 6 \\
Kuvvetli hafiza $(1,3,8)$ & 3 \\
Müziğe ve görsel sanatlara yatkınlık $(9,11,12)$ & 3 \\
Kendinden yaşça büyüklerle anlaşma $(1,10)$ & 2 \\
\hline
\end{tabular}




\begin{tabular}{ll}
\hline Kod & $f$ \\
\hline Kavram ve nesneler arasında geçişler yapabilme (10) & 1 \\
Sosyal olma ve sorumluluk bakımından güçlükler (4) & 1 \\
\hline
\end{tabular}

Tablo 2'de görüldüğü üzere öğretmenlerin 8'i gelişimin kritik dönemlerini ve zihinsel faaliyetleri erken tamamlama, 6'sı uyaranlara farklı boyutlarda bakabilme, 6'sı merakıyla çok soru sorma ve ikna olmama, 3'ü kuvvetli hafiza, 3'ü müzik ve görsel sanatlara yatkınlık, 2'si kendinden yaşça büyüklerle anlaşma, 1'i kavram ve nesneler arasında geçişler yapabilme, 1'i sosyal olma ve sorumluluk alma bakımından yaşanan güçlükler olarak düşüncelerini ifade etmişlerdir. Bu düşüncelere ilişkin öğretmenlerin ifadeleri sırası ile aşağıda yer almaktadır.

Ö2: “(...) her özellikleri daha erkendir. Yaşıtlarından erken konuşma, yürüme, okuma yazma öğrenme, gelişmiş göz takibi ve görsel algı, iletişim yeteneği, zengin kelime dağarcığı, işlem kabiliyeti vb”. Ö3: "(...) sorulan sorulara farklı yorumlar yapabilir. Konuşulan, dinlenen vs bir şeyi farklı algılayabilirler.". Ö1: "(...) meraklıdırlar ve meraklı oldukları konularda çok soru sorarlar. Okuma vs becerileri de olmadığı için aldığı cevaplar ikna edici olmayabilir.”. Ö8: "(...) gördügüu, duyduğu bir şeyi unutmazlar.”. Ö9: "(..) bir ses ya da görsel öğeye karşı duyarlılığı yüksek olur. Çok erken yaşlarda iyi çizebilme, bir çalgı aleti çalabilme vs olduğu görülüyor". Ö1: "(...) her dönemde olduğu gibi erken dönemde de kendinden yaşça büyük bireyler ile birlikte olmak isteyebilirler"...

Öğretmenlere üçüncü soru olarak "Üstün zekâlı ve yetenekli çocukların ne zaman tanılanmalıdır?" sorulmuştur. Öğretmenlerin soruya verdikleri cevaplar Tablo 3'de verilmiştir.

Tablo 3. Öğretmenlerin Çocukların Ne Zaman Tanılanmasına İlişkin Görüşleri

\begin{tabular}{lc}
\hline Kod & $f$ \\
\hline Tanılamanın yapılabildiği en erken dönem $(1,2,4,6,7,8,10,11,12,13$ & 10 \\
Okulöncesi dönemden de önce $(1,6,12)$ & 3 \\
Doğum ve öncesi dönemde (1) & 1 \\
Yetenek ne zaman görülürse (3) & 1 \\
Ortaokul döneminde (5) & 1 \\
Hiçbir zaman (9) & 1 \\
\hline
\end{tabular}

Tablo 3'de görüldüğü üzere öğretmenlerin 10'u olabildiğince erken dönem, 3’ü okul öncesi dönemden de önce, 1'i doğum ve öncesi dönemde, 1'i yetenek ne zaman görülürse, 1'i ortaokul döneminde, 1'i hiçbir zaman tanılanma yapılması gerektiği yönünde düşüncelerini ifade etmişlerdir. Bu düşüncelere iliş̧in öğretmenlerin ifadeleri sırası ile aşağıda yer almaktadır.

Ö1: “(...) tanılamanın uygun şartlarının olduğu en erken dönemde. Testler ve diğer veriler en doğru şekilde tanılamayı en erken ne zaman yapabilecekse o zaman yapılmalıdır". Ö6: "(...)okulöncesine girmeden önce çocuklar hakkında kararlar vermektedirler". Ö1: "(...) birçok gelişmiş ülke daha anne karnında çocukları takip ederek fikir sahibi olmaktadır. Doğumdan itibaren de kalıtım vs faktörleri dikkate alarak tanı için çaIışmalar yapmaktadırlar". Ö3: "(...) çocuğun üzerindeki sosyal ortamın yarattğ̆ı baskılardan yeteneğini göstermesine engel olabilir bu sebeple çocuğun yeteneğinin geç farkına varılabilir ya da yetenek çocuk rahatladığında ortaya çıkabilir, bu sebeple uygun zaman görülünce ortaya çıkan yeteneği tanılamak gerekir"....

Öğretmenlere üçüncü soru olarak "Üstün zekâlı ve yetenekli çocukların erken dönemde tanılanması için gerekçeler ne olabilir?” sorulmuştur. Öğretmenlerin soruya verdikleri cevaplar Tablo 4'de verilmiştir.

Tablo 4. Öğretmenlerin Erken Tanılama Gerekçelerine İlişkin Görüşleri

\begin{tabular}{lc}
\hline Kod & $f$ \\
\hline Erken müdahale edip yeteneği en üst seviyeye çıkarma $(1,3,4,5,6,7,8,9,10,11)$ & 11 \\
Yeteneği ve ihtiyaçlarına göre erken eğitim programları alması $(1,5,6,7,8,9,10,11,12)$ & 9 \\
Eğitim programlarına uygun materyal, ilke ve strateji geliştirme $(1,5,9,11,12)$ & 5 \\
Aile ve öğretmene yönelik eğitim programların verilmesi $(1,5,6,7,8)$ & 5 \\
Sosyal, duygusal ve ahlaki ihtiyaçlarının karşılanması $(1,3,4,6,7)$ & 5 \\
Onların kapasite ve hızlarına uygun öğrenme ortamları ve programları $(3,5,7,8)$ & 4 \\
Nasıl bir eğitim sürecinin belirlenmesi $(8,10)$ & 2 \\
\hline
\end{tabular}

Tablo 4'de görüldüğü üzere üstün zekâlı ve yetenekli çocukların erken dönemde tanılanma gerekçelerini öğretmen- 
lerden 11'i erken müdahale edip yeteneği en üst seviyeye çıkarma, 9’u yeteneği ve ihtiyaçlarına göre erken eğitim programları alması, 5’i eğitim programlarına uygun materyal, ilke ve strateji geliştirme, 5'i ve öğretmene yönelik eğitim programların verilmesi, 5'i sosyal, duygusal ve ahlaki ihtiyaçlarının karşılanması, 4'ü onaların kapasite ve hızlarına uygun öğrenme ortamları ve programları hazırlanması, 2'si nasıl bir eğitim sürecinin belirlenmesi olarak düşüncelerini ifade etmişlerdir. Bu düşüncelere ilişkin öğretmenlerin ifadeleri sırası ile aşağıda yer almaktadır.

Ö1: "(...) ne kadar erken dönemde tespit edebilirsek ileride o kadar başarılı olabiliriz. Belki çocuğun deha düzeyinde üst performans göstermesinde bile etkili olabilir". Ö5: "(...) erken dönemde tespit edilen yeteneği yönünde eğitim programları almalı ve yetenekli olduğu alan daha da ilerletilmelidir". Ög: "(...) çocuğa yönelik programlar geliştirilip, bu programlar uygun materyaller, öğrenme stratejileri geliştirilmelidir". Ö8: "(...) çocuk erken tanılanırsa öğretmen ve aile de buna yönelik ne yapacağını bilecektir. Öğretmen ve ailenin ihtiyaçları yönünde de eğitimler ve rehberlik hizmetleri verilecektir". Ö7: "(...) çocuğun bu dönemdeki belirginleşen sosyal, duygusal ve yeteneklerini toplum için faydalı yönde kullanması beklenen ahlaki değer gereksinimleri karşılanması bakımından"...

\section{Tartışma}

Araştırmanın dört farklı bulgusunun ilkinde öğretmenler üstün zekâ ve yetenek kavramının ne olduğunu bilmektedir. Benzer sonuçlar Tezcan (2012) çalışmasında da görülmektedir. Okulöncesi öğretmenleri üstün zekâlı ve yetenek kavramını yüksek bilişsel kabiliyet, akranlarından ileri öğrenebilme, ilişki örüntü görebilme, keşfetme gibi özelliklerle açıklamıştır. Kıldan (2011) çalışmasında da öğretmenler üstün zekâ ve yetenek niteliklerini meraklı araştırmacı, akranlarından yüksek kapasite, konuşma anlamada ilerilik ve yaratıcılık olarak ifade etmiştir. Üstün zekâ ve yetenek üstün zihinsel güç, zihinsel performans olarak da öğretmenler tarafindan ifade edilmektedir (Rohrer, 1995).

Araştırmanın ikinci bulgusundan öğretmenler okul öncesi dönemde üstün zekâlı ve yetenekli öğrencilerin özelliklerini bilmektedir. Üstün zekâlı ve yetenekli çocukların kolay ikna olmadığı, meraklı oldukları, kavramlar arası ilişkileri iyi kurabildikleri bilinmektedir (Galloway ve Porath, 1997). Karadağ’a göre (2015), üstün zekâlı ve yetenekli çocuklar erken dönemde güçlü zihinsel faaliyet, merak, kolay ikna olmama, yüksek hafizaya sahip olma, sanatsal faaliyetlere ilgili olma, kavramlar arası ilişkileri görebilme gibi özelliklere sahiptir. Bozkurt’a göre (2007) üstün zekâlı ve yetenekli çocuklar erken dönemde sosyal ve zihinsel olarak ileri düzeyde gelişim göstermektedir. Bu gelişimsel özellikler çeşitli beceriler olarak ifade edilmiştir.

Araştırmanın üçüncü bulgusunda öğretmenler üstün zekâlı ve yetenekli çocukların erken tanılanması yönünde eğilime sahiptir. Dağlıoğlu (2004)’na göre çocukların erken dönemde tanılanması önemlidir. Erken dönemde tanılanan üstün zekâlı ve yetenekli çocuklara yönelik eğitim planlamaları yapılmalıdır. Scott ve Delgado (2005) erken çocukluk döneminde üstün zekâlı ve yetenekli çocukların özelliklerinin farkında olunmalı ve çocuklar erken dönemde tanılanmalıdır. Kurt (2008), RSPM Plus Testi ile üstün zekâlı ve yetenekli çocukları 5,5-6,5 yaş arasında tespit edilmiştir. Erken dönemde yeteneklerin tespiti önemlidir. Çalışmada da bu yetenek alanlarından erken matematik yeteneği tespit edilmektedir. Çetinkaya (2007) , üstün zekâlı yetenekli çocukları 6,5 yaşından itibaren tespit etmiştir. Erken dönemde üstün zekâlı ve yetenekli çocukların tespitinin önemi çalışmada vurgulanan sonuçlar arasında yer almaktadır.

Araştırmanın son bulgusunda üstün zekâlı ve yetenekli çocukların erken dönemde tanılanmasının onların erken eğitim programlarından yararlanması, yeteneklerini en üst seviyeye çıkarılabileceği, aile ve öğretmenlerinin de eğitilerek onlara faydalı bireyler olabileceği verilerine ulaşılmıştır. Shaklee (1992) göre, üstün zekâlı ve yetenekli bireyler için okul öncesi dönemde eğitim programlarının düzenlenmelidir. Özellikle azınlık bölgeleri, kırsalda yaşayanlar ve dezavantajı olan çocuklar için bilinçli olunması gerektiği ifade edilmiştir. Dönmez Baykoç ve Kurt'a (2004) göre ise Bilim Sanat Merkezleri'ne devam edecek çocuklar okulöncesinden de erken belirlenerek eğitimlerle desteklenmelidir. Doğan, Tekcan ve Cürebal'a (2004) göre üstün bireylere yönelik ilgili uzmanlarla ihtiyaç ve beklentilerini karşılayıcı programlar hazırlanmalıdır. Kerem ve Kınık’a (2004) göre, ülkemizde bu çocukları erken yaşlarda tespit ederen onların ilgi ihtiyaçlarına göre eğitim programları hazırlanmalıdır.

Öğretmen ve ailelerin üstün zekâlı ve yetenekli çocuklar hakkında eğitim ve danışmanlık almaları önemlidir. Dağlığlu'na (2004) göre okulöncesi dönemde en büyük görev ailenindir. Evde aile okulda öğretmen çocuğun yeteneklerini geliştirici girişimlerde bulunmalıdır. Dağlıoğlu ve Suveren'e (2013) göre üstün yetenekli çocukları belirlemede aileler daha etkilidir. Uygulanan testlerden elde edilen puanlar dikkate alındığında, öğretmenlerin ailelerden daha tutarlı değerlendirmeler yaptıkları gözlenmiştir. Jarosewich, Pfeiffer ve Morris (2002), üstün yetenekli çocukların belirlenmesinde öğretmen ve ailelerin gözlemlerinden yararlanmıştır. Benito ve Moro (1999) aileleri ve çocukların sonuçlarına dayalı bir değerlendirme yöntemi ile üstün zekâlı ve yetenekli çocukların belirlenmiştir. Coşar, Çetinkaya ve Çetinkaya (2015) çalışmalarında 
üstün zekâlı ve yetenekli çocuklarla çalışan öğretmenlerin çocukların erken tanılanarak eğitime başlamaları gerektiğini vurgulamışlardır. Pegnato ve Birch (1959), araştırmalarında öğretmenlerin üstün zekâlı ve yetenekli çocukların özellikleri konusunda yeterli bilgiye sahip olmadıklarını göstermektedir. Hafenstein ve Tucker (1995), erken çocukluk döneminde üstün zekâlı çocukların tespit edilmesi için çok yönlü bilgilerle karar verilmiştir. Oğurlu ve Çetinkaya (2012) çalışmalarında çocukların tanılanmasında ailelerin çocuklarında gözlemledikleri özellikleri dikkate almışlardır.

Öğretmenler üstün zekâlı ve yetenekli çocukların erken dönemde tanılanması için uygun eğitim ortamlarının sağlanması gerekliliğini de vurgulamıştı. İnsanlığın seviyesini yükseltecek eğitim ortamı hem bireysel hem de toplumsal geliş̧mişliğin sağlanmasında önemli bir etmen olarak karşımızda durmaktadır (Hökelekli ve Gündüz, 2004). Megep'de (2007), özel yetenekli çocuklar ilgileri ve intiyaçları bakımından benzer özelliklere sahip bireylerle iletişim kurmalıdır. Araştrrmaya katılan öğretmenler sosyal açılardan çocukların erken dönemlerde zorlanabileceğini söylemişlerdir. Davaslıgil ve Leana'ya (2004) göre, bu çocuklar toplumdan dışlanmadan kendilerini anlayan ve kendisi gibi olan kişilerle iletişime geçmeleri gerektiğini ifade etmişlerdir. Öğrencilerin gelişimleri bir bütün olarak ele alınarak sosyo-duygusal yönlerden gelişmelerini sağlayacak etkinliklere eğitimlerinde yer verilmelidir.

\section{Öneriler}

Bir toplumun ilerlemesinde önemli yere sahip olan üstün zekâlı ve yetenekli çocukların erken yaşlarda tespit edilmesi önemlidir. Erken dönemde çocukların tanılanması ve yetenekleri yönünde eğitim almaları için ulusal politikaların geliştirilmesi gerekmektedir. Her toplum üstün zekâlı ve yetenekli bireylerini kendi içerisinden çıkarmaktadır. Genelde çocuğun yeteneğinin ailece fark edilmemesi ya da fark edilse bile gözardı edilmesi çocuğun ıskalanmasına neden olur. Bu yüzden çocukların erken yaşta keşfedilmeleri için ailelere yönelik erken eğitim programları, okul-aile birliktelikli ortak çalışma programları, belediyelerin vb desteklediği üstün çocukları keşfetme ve belirleme çalışmaları yapılmalıdır.

Öğrencilerin tanılanma sürecinde en uzun süre gözlem yapan kişiler öğretmen ve aileleridir. Bu anlamda başta öğretmenler olmak üzere ailelere farkındalık eğitimleri ve seminerleri düzenlenmelidir. BíLSEM öğretmenleri okulöncesi dönemde çocuklarla çalışmasa da çalıştı̆̆ yaş grubu ile hemen hemen aynı özellikleri gösteren erken dönem üstün zekâlı ve yetenekli çocuklarla çalışabilme konusunda donanımlı hale getirilmelidir. Bununla birlikte çocukları aday gösterecek olan anaokulu, kreş vs kurumlardaki okulöncesi öğretmenlerine de çocukların özellikleri ve tanılamada dikkat edilecek hususlar konusunda bilgiler verilmelidir. Öğretmenler aday göstereceği çocukta nelere dikkat edeceğini bilmelidirler. Eğitim Fakültesinin okul öncesi öğretmenliği ya da üstün zekâlılar eğitiminde okuyan öğretmen adaylarına da tanılamaya uygun dersler koyulmalıdır.

\section{Kaynakça}

Alma, S. (2015). Üstün yetenekliliği derecelendirme ölçekleri okulöncesi/ananaokulu formu (Grs-p)'nun Türkçeye uyarlanması (Yayımlanmamış Doktora Tezi). Selçuk Üniversitesi Sosyal Bilimler Enstitüsü, Konya

Baykoç, N. (2011). Üstün ve Özel Yetenekli Çocuklar ve Eğitimleri. Baykoç, N.(Ed). Özel Gereksinimli Çocuklar ve Özel Eğitim. Ankara: Eğiten Kitap.

Benito, Y. ve Moro, J. (1999). An emprically-based proposal for screening in the early identification of intellectually gifted students. Gifted Child International. 14(2), 80-91.

Bogdan, R.C. ve Biklen, S. K.(2007). Qualitative research for education. Boston: Pearson Education Inc.

Cosar, G., Cetinkaya, C., ve Cetinkaya, C. (2015). Investigating the preschool training for gifted and talented students on gifted school teachers' view. Journal for the Education of Gifted Young Scientists, 3 (1), 13-21. DOI: http://dx.doi.org/ 10.17478/JEGYS.2015110747

Cutts, N.,E. ve Moseley, N. (2001). Üstün Zekâlı ve Yetenekli Çocukların Eğitimi. İsmail Ersevim (Çev.). İstanbul: Özgür Yayınları.

Çetinkaya, Ç. (2013a). Sıradışı konular çalışma etkinliklerinin yaratıııı̆a etkisi (Yayımlanmamış Doktora Tezi). Çanakkale Onsekiz Mart Üniversitesi Eğitim Bilimleri Enstitüsü, Çanakkale.

Çetinkaya, Ç. (2013b). Sakarya science and art center nature education programme. Journal of Environmental Protection and Ecology JEPE, 14 (3A), 1317-1324

Çetinkaya, Ç. (2007). Raven'in ilerleyen matisler plus testi'nin 6,5-8 yas çocukları üzerinde geçerlik, güvenirlik, ön norm çalısmaları ve motivasyon stilleri tespiti ile ilişkisinin incelenmesi (Yayımlanmamış Yüksek Lisans Tezi). İstanbul Üniversitesi Sosyal Bilimler Enstitüsü, İstanbul.

Damasio, A. (1999). Descartes'in yanılgısı. Varlık Yayınları. İstanbul

Davaslıgil, Ü. (2004). Üstün çocuklar. Şirin, M.R., Kulaksızoğlu, A. ve Bilgili, A. E. (Ed.), I Türkiye Üstün Yetenekli Çocuklar Kongresi Makaleler Kitabı (211-220). İstanbul: Çocuk Vakfi Yayınları: 63.

Davaslıgil, Ü ve Leana, M. (2004). Üstün Zekâlıların Eğitimi Projesi. Şirin, M.R., Kulaksızoğlu, A. ve Bilgili, A. E. (Ed.), I Türkiye Üstün Yetenekli Çocuklar Kongresi Bildiriler Kitabı (85-100). İstanbul: Çocuk Vakfi Yayınları: 64. 
Dağlıoğlu, E. (2004). Okul öncesi eğitim kurumuna devam eden beş-alt yaş grubunda ve matematik alanında üstün yetenekli olan çocukların sosyodemogrofik özellikler bakımından incelenmesi. Şirin, M.R., Kulaksızoğlu, A. ve Bilgili, A. E. (Ed.), I Türkiye Üstün Yetenekli Çocuklar Kongresi Bildiriler Kitabı (247-262). İstanbul: Çocuk Vakfi Yayınları: 64.

Dağlıoğlu, E. ve Suveren, S. (2013). Okul öncesi dönem üstün yetenekli çocukların belirlenmesinde öğretmen ve aile görüsleri ile çocukların performanslarının tutarlıı̆ı̆ının incelenmesi. Kuram ve Uygulamada Eğitim Bilimleri - EducationalSciences: Theory \& Practice, 13 (1), $431-453$.

Doğan, M., Tekcan, N. ve Cürebal, F. (2004). Üstün ve özel yetenekli öğrencilere yönelik bir okul modeli: Tevitöl. Şirin, M.R., Kulaksızoğlu, A. ve Bilgili, A. E. (Ed.), I Türkiye Üstün Yetenekli Çocuklar Kongresi Bildiriler Kitabı (101-106). İstanbul: Çocuk Vakfi Yayınları: 64.

Dönmez Baykoç, N. ve Kurt, Ş. (2004). Bebeklik ve okul öncesi dönemde üstün yetenekli çocukların ve ailelerinin yönlendirilmesi. Şirin, M.R., Kulaksızoğlu, A. ve Bilgili, A. E. (Ed.), I Türkiye Üstün Yetenekli Çocuklar Kongresi Bildiriler Kitabı (393-400). İstanbul: Çocuk Vakfi Yayınları: 64.

Ercan, F. (2013). Fen alanında üstün yetenekli öğrencilerin tanılanmasına yönelik bir model geliştirme önerisi. (Yayınlanmamış doktora tezi), Abant İzzet Baysal Üniversitesi, Bolu.

Freeman, J. (1985). The psychology of gifted children, perspectives on development and education. Suffolk: John Wileyand Sons Ltd.

Feldhussen, J. ve Kolloff, P. B. (1986). The purdue three-stage enrichment model for gifted education at the elementary level In J.S. Renzulli (Ed.) System and Models for Developing Programs for The Gifted and Talented. Mansfield Center, CT: Creative Learning Press.

Galloway, B. ve Porath, M. (1997). Parent and teacher views of gifted children's social abilities. Roeper Review, 20 (2), 118-121

Gagné, F. (1995). From giftedness to talent a developmental model and its impact on language of the field. Roper Review, $18,103-111$.

Gür, Ç. (2006). Sanat Eğitim Programının Üst Sosyo-Ekonomik Düzeyden Gelen Altı Yaş Üstün Yetenekli Çocukların Çizim Becerilerine Etkisi (Doktora Tezi). Gazi Üniversitesi Eğitim Bilimleri Enstitüsü, Ankara.

Hafenstein N. L. ve Tucker, B. (1995). Case studies in diversity: Individual differences in abilities and traits of young gifted children. Paper presented at the annual meeting of the American Educational Research Association, San Francisco, CA. (ERIC Document Reproduction Service No. ED385047)

Harrison, C. (2004). Giftedness in early childhood: Search for complexity and connection. Roeper Review, 26 (2), 78-84.

Heller, K.A. (2001). Hochbegabung im Kindes- und Jugendalter. High ability in childhood and youth (2.Baskı). Göttingen: Hogrefe.

Heller, K.A.,Perleth, C. ve Lim, T.K. (2005). The Munich model of giftedness designed to identify and promote gifted students. In R.J. Sternberg ve J.E. Davidson (Ed.), Conceptions of giftedness (2. Baskı, syf. 147-170). New York: Cambridge UniversityPress.

Heller, K. A. ve Schofield, N. J. (2008). Identification and nurturing the gifted from an international perspective. Pfeiffer, S. (Ed). Handbook of giftednessin children, (pp. 93-114). Springer US.

Hodge, K. ve Kemp,C. (2002). The role of invitational curriculum in the identification of giftedness in young children. Australian Journal of Early Childhood, 27 (1), 33-38.

Hökelekli, H. ve Gündüz, T. (2004). Üstün yetenekli çocukların karakter özellikleri ve değerler eğitimi. Şirin, M.R., Kulaksızoğlu, A. ve Bilgili, A. E. (Ed.), I Türkiye Üstün Yetenekli Çocuklar Kongresi Bildiriler Kitabı (131-144). İstanbul: Çocuk Vakfi Yayınları: 64.

Jarosewich, T., Pfeiffer, S. I. ve Morris, J. (2002). Identifying gifted students using teacher rating scales: A review of existing instruments. Journal of Psychoeducational Assessment, 20 (4), 322-336

Johnson, B., ve Cristensen, L. (2014). Educational research: Quantitative, qualitative, and mixed approaches. Thousand Oaks, Calif: Sage.

Karadağ, F. (2015). Okul öncesi dönemde potansiyel üstün zekâlı çocukların belirlenmesi. (Yayımlanmamış Yüksek Lisans Tezi). Ege Üniversitesi Eğitim Bilimleri Enstitüsü, İzmir.

Karasar, N. (2011). Bilimsel araştırma yöntemi. Ankara: Nobel Yayın Evi.

Kelemen, G. (2012). Identification of highly gifted children. Exedra Journal, (6), 43-55.

Kerem, E.A. ve Kınık, E. (2004). Erken Çocukluk Eğitiminde Üstün Yetenekli Çocuklara "Kimlikli Bebekler” Çalışmasıyla Farklı Bir Bakış: Bir Uygulama Örneği “Deha Bebek”. Şirin, M.R., Kulaksızoğlu, A. ve Bilgili, A. E. (Ed.), I Türkiye Üstün Yetenekli Çocuklar Kongresi Bildiriler Kitabı (161-168). İstanbul: Çocuk Vakfi Yayınları: 64.

Kıldan, O. (2011). Okul öncesi öğretmenlerinin üstün yetenekli çocuklar hakkındaki görüşleri. Kastamonu Eğitim Dergisi, 19 (3), $805-818$

Koshy, V. (2001). Teaching mathematics to able children. London: David Fulton Publishers.

Kurt, E. (2008). Raven Spm Plus Testi 5.5-6.5 Yaş Geçerlik, Güvenirlik, Ön Norm Çalışmalarına Göre Üstün Zekalı Olan ve Olmayan Öğrencilerin Erken Matematik Yeteneklerinin Karşılaştırılması (Yayımlanmamış Yüksek Lisans Tezi). İstanbul Üniversitesi Sosyal Bilimler Enstitüsü, İstanbul.

Maker, C. J. (2003). New directions in enrichment and acceleration, In. N. Colengelo ve G. Davis (Ed.), Handbook of Gifted Education, (pp 163-173), Boston: Allynand Bacon.

Marland, S. P. (1972). Education of Gifted and Talented. W D.C.: US Office of Education.

MEB, (2016). Bilim ve Sanat Merkezleri Yönergesi.

MEB, (2009). Bilim ve Sanat Merkezleri Yönergesi. Yönerge, Mart 2009/2618 sayılı Tebliğler Dergisi'nde yayımlanan 5'inci maddesiyle değiştirilmiştir. 
MEGEP (2007). Hayat Boyu Öğrenme Genel Müdürlüğü, Mesleki Eğitim ve Öğretim Sisteminin Güçlendirilmesi Projesi. http://hbogm. meb.gov.tr/modulerprogramlar/kursprogramlari/cocukgelisim/moduller/ustunzekaveozelyetene kliler.pdf

Merriam, S.B. (2009) Qualitative research: A guide to design and implemantation. San Francisco, CA: Jossey- Bass.

Miklewska, A.,Kaczmarek, M. Ve Strelau, J. (2006). The relationship between temperament and intelligence: Cross-sectionalstudy in successive age groups. Personality and Individual Diffrences. 40, 643-654.

Moore, A. D. (1992). Gifted and talented children and youth (Ed. L. M. Bullock). Exceptionalities in Children and Youth. USA: Allynand Bacon Inc. s. 420-448

Oğurlu, U. ve Çetinkaya, C. (2012). Identification of preschool gifted children characteristics based on parents'. The Online Journal of Counseling and Education. 1(3), 41-56.

Özbay, Y. (2013). Üstün yetenekli çocuklar ve aileleri. Ankara: Aile ve sosyal Politikalar Bakanlığı

Patton, M. Q. (2014). Nitel araştırma ve değerlendirme yöntemleri. Mesut Bütün ve Selçuk Beşir Demir (Çev. Edt.). Ankara: Pegem Akademi. Passow, H. (2004). The nature of giftedness and talent. Definitions and conceptions of giftedness. Ed. R.T. Stenberg, California: Corwin Press. Pegnato, C. W. ve Birch, J. W. (1959). Locating gifted children in junior high school. Exceptional Children, 25, 300-304

Pfeiffer, S. I. (2008). Handbook of giftedness in children: Psycho educational theory, research and best practices. FL, USA; Springer

Porter, L. (1999).Gifted young children. Open University Press, Buckhingham

Renzulli, J. S. (1978). What makes giftedness? Reexamining a definition. Phi Delta Kappan, 60(3).

Rohrer, J. C. (1995). Primary teacher conceptions of giftedness: Image, evidence, and nonevidence. Journal for the Education of the Gifted, 18, 269-283.

Sak, U. (2010). Üstün zekâlılar özellikleri, tanılanmaları, eğitimleri. Ankara: Maya Akademi Yayınevi.

Scott, M. S. ve Delgado, C. F. (2005). Identifying cognitively gifted minority students in preschool. Gifted Child Quarterly, 49 (3), $199-210$.

Schofield, N.J. ve Hotulainen, R. (2004). Does all cream rise? The plight of unsupported gifted children. Psychology Science, 46, 379-386.

Shaklee, B. D. (1992). Identification of young gifted students. Journal for the Education of the Gifted, 15(2), 134-144.

Sisk, D. (1987). Creative teaching of the gifted. USA: McGraw-Hilllnc.

Sousa, D. A. (2003). How the gifted brain learners. California: Corwin Press.

Stapf, A. (2003). Hochbegabte Kinder (Highly gifted children). München: C.H. Beck.

Sternberg, R. J.,Jarvin, L. ve Grigorenko, E. L. (2010). Explorations in giftedness. Cambridge UniversityPress

Sternberg, R. J. (2003). Giftedness according to the theory of successful intelligence. N. Colangelo ve G. Davis (Eds.), Handbook of gifted education. Boston: Allyn \& Bacon.

Sternberg, R. J. (1999). A triarchic approach to the understanding and assessment of intelligence in multicultural populations. Journal of School Psychology, 37.

Suveren, S. (2006). Anasınıfina devam eden çocuklar arasından üstün yetenekli olanların belirlenmesi (Yüksek Lisans Tezi). Abant İzzet Baysal Üniversitesi Sosyal Bilimler Enstitüsü, Bolu.

Şahin, F. ve Çetinkaya, Ç. (2015). An investigation of the effectiveness and efficiency of classroom teachers in the identification of gifted students. Turkish Journal of Giftedness and Education, 5 (2), 133-146.

Tezcan, F. (2012). Perception of Early Childhood Teachers Towards Young Gifted Children and Their Education. (Unpublished Master Thesis). Middle East Technical University, The Graduate School of Social Science, Ankara.

Topses, G. (1992). Eğitim sürecinde insan ve psikoloji. Ankara: Gazi Büro Evi.

Tuttle, F. B. ve Becker, L. (1980). Characteristics and identification of gifted and talented students. National Education Association Washington. D.C Uzun, M. (2004). Üstün yetenekli çocuklar el kitabı. İstanbul: Çocuk Vakfi Yayınları.

Webb, J. T., Meckstroth, E. A. ve Tolan, S. S. (2003). Guiding the gifted child. Gifted Psychology Press, Arizona, USA: Scottsdale.

Weiten, W. (1995). Themen \& variation. CA: Brooks/Cole Publising Company.

Winner, E. (1996) Gifted children myths and realities. Basic Books, New York.

Yıldırım, A ve Şimşek, H. (2013). Sosyal Bilimlerde nitel araştırma yöntemleri. Ankara: Seçkin Yayıncılık

| Kastamonu Eğitim Dergisi, 27(3), 2019| 